\title{
DOUTRINA TOBAR E DOUTRINA ESTRADA: COMO A DOUTRINA DE RECONHECIMENTO DE GOVERNO PODE AJUDAR NA RESTAURAÇÃO DA DEMOCRACIA EM MIANMAR
}

\author{
Simone Alvarez Lima ${ }^{1}$
}

\section{RESUMO}

Em novembro de 2020, o partido Liga Nacional pela Democracia venceu as eleições presidenciais em Mianmar, entretanto, os militares entenderam que as eleições foram fraudulentas e tiraram o poder do Presidente Win Myint. Desde então, Mianmar sofre com a ditadura e violações a direitos humanos. Os Estados podem adotar a doutrina Tobar ou a Doutrina Estrada de reconhecimento de governo, considerando que a Doutrina Tobar pode ser mais efetiva no auxílio ao retorno à democracia, enquanto a doutrina Estrada pode estimular governos golpistas a assumirem o poder em virtude da impunidade oriunda do princípio da não intervenção.

Palavras-chave: Doutrina Tobar; Doutrina Estrada; reconhecimento de governo; Mianmar; golpe militar.

\section{TOBAR DOCTRINE AND ESTRADA DOCTRINE: HOW THE DOCTRINE OF GOVERNMENT RECOGNITION CAN HELP IN THE RESTORATION OF DEMOCRACY IN MYANMAR}

\begin{abstract}
In November 2020, the National League for Democracy party won the presidential elections in Myanmar, however, the military understood that the elections were fraudulent and took power away from President Win Myint. Since then, Myanmar has suffered from dictatorship and human rights violations. States can adopt the Tobar Doctrine or the Estrada Doctrine of government recognition, whereas the Tobar Doctrine can be more effective in aiding the return to democracy, while the Estrada Doctrine can encourage coup governments to assume power due to impunity arising from the principle of non-intervention.
\end{abstract}

Keywords: Tobar Doutricne; Estrada Doutricne; government recognition; Myanmar; military coup.

\section{INTRODUÇÃO}

Em 2021, Mianmar sofreu um golpe de estado por parte de militares que entenderam que as eleições vencidas, em 2020, pelo partido Liga Nacional pela Democracia, foram

\footnotetext{
${ }^{1}$ Professora de Direito na Universidade Estácio de Sá. Doutora em Direito, na linha de pesquisa Direitos Fundamentais e Novos Direitos pela Universidade Estácio de Sá e membro da Comissão de Direito Internacional da OAB/RJ. E-mail: sissyalvarez22@yahoo.com.br.
} 
fraudulentas e, em nome do estado de defesa previsto na Constituição Federal de Mianmar, tomou, à força, o poder do Presidente democraticamente eleito.

O presente artigo tem como objetivo dissertar sobre o golpe militar ocorrido em Mianmar e trazer uma ideia prospectiva a respeito de soluções que os Estados da sociedade internacional poderiam adotar, com base na Doutrina Tobar de reconhecimento de governo, a fim de auxiliar no retorno da democracia em Mianmar.

O primeiro item é destinado a trazer aspectos históricos da relação entre Mianmar e a Ditadura Militar e a explicar quais são os direitos humanos previstos na Declaração Universal de Direitos Humanos que foram violados em virtude da tomada militar do poder. Neste item, é explicado que Mianmar é membro da Organização das Nações Unidas e, por isso, deve observar os ditames dessa organização.

O segundo item explica a doutrina Tobar de reconhecimento de governo, enfocando no fato de que esta sugere que os Estados da sociedade internacional não reconheçam governos que tenham chegado ao poder por meio da ambição ou golpe de Estado e relaciona a sua importância no tocante à adoção de atos unilaterais de Estados que desejam ajudar a população de Mianmar a alcançar o objetivo de restaurar a democracia no país.

Já o terceiro item enfoca a doutrina Estrada, explicando que países que optam pela neutralidade, por entenderem que não é de suas respectivas competências reconhecer a legitimidade ou não do Governo de outro Estado, estão contribuindo para a manutenção de Governos ilegítimos no poder, em prejuízo aos direitos humanos, que são normas jus cogens e erga omnes.

Por fim, o último item do presente artigo é destinado a mostrar como os Estados, por meio da Doutrina Tobar podem auxiliar Mianmar a recuperar a democracia e que essa postura não viola à Carta das Nações Unidas, afinal, não se trata de ferir a autodeterminação dos povos, mas, sim, de restaurar a democracia perdida, além disso, traz recomendações à sociedade internacional do que pode ser feito para restaurar os direitos humanos violados em Mianmar.

Essa pesquisa se justifica em virtude se ser um tema atinente à democracia, algo que, nos últimos anos, tem sido colocada em risco em diversos países, inclusive no Brasil. Assim, trazer o exemplo da reimplantação da Ditadura em Mianmar servirá para refletir sobre os impactos negativos da ditadura em uma sociedade acostumada já acostumada com a democracia, ainda que falha e sobre até que ponto a neutralidade dos atores da sociedade 
internacional, com base na Doutrina Estrada, pode servir de estímulo à manutenção de governos golpistas.

Para a elaboração deste artigo foi adotado o método hipotético-dedutivo, pois parte da hipótese de que se os Estados finalizassem suas relações diplomáticas e econômicas com Mianmar, os militarem acabariam cedendo e a democracia retornaria. Os dados foram obtidos por meio de pesquisa bibliográfica e documental, devido a utilização de livros, artigos científicos e legislação.

\section{1-DA VIOLAÇÃO AOS DIREITOS HUMANOS EM VIRTUDE DO GOLPE DE ESTADO EM MIANMAR}

Em $1^{\circ}$ de fevereiro de 2021, Mianmar sofreu um golpe de Estado por parte do Exército Tatmadaw, liderado por Min Aung Hlaing que, em virtude de não reconhecer a vitória do partido Liga Nacional pela Democracia e ocupou o Senado e o Parlamento e ordenou a detenção dos líderes do governo, tais como o Presidente Win Myint, a Conselheira de Estado, Aung San Suu Kyi, vencedora do Prêmio Nobel da Paz, líderes políticos, defensores de direitos humanos, jornalistas, ativistas dentre outros considerados nocivos pelos militares.

De acordo com Stefano (2021), esse golpe ocorreu devido ao fato de que o Partido União de Solidariedade e Desenvolvimento, apoiado pelos militares, ter tido um resultado ruim nessas eleições de 2020, quando comparado ao resultado obtido em 2015, perdendo cadeiras no Parlamento.

Antes de abordar como os Estados devem se portar diante do golpe militar, é relevante explicar a origem histórica do que envolve essa tomada pelo poder por parte dos militares em afronta à Constituição do país, eis que o militarismo faz parte do histórico de Mianmar.

Mianmar, cujo nome original era Birmânia, é um país que está localizado no continente asiático e foi uma colônia inglesa entre 1824 (período em que foi anexado à Índia) e 1948 (ano da independência), a qual reunia diversas etnias que eram rivais, afinal, colonizadores estavam mais preocupados com aspectos territoriais do que com as etnias das pessoas que estavam colonizando. Apesar do presente artigo não focar nas questões étnicas de 
Mianmar, até hoje o país sofre com a rivalidade entre os budistas, que são maioria, e os muçulmanos rohingyas, envolvendo questões de limpeza étnica e a frequente migração de milhares de rohingyas para Bangladesh. (BBC NEWS, 2017)

O nome Birmânia foi mantido desde 1885 e apenas alterado para União de Mianmar em 1989. Atualmente, o país asiático faz fronteira com a China, Tailândia, Laos, Índia e Bangladesh, detentor de um território de, aproximadamente, $677.000 \mathrm{~km}^{2}$.

Xavier e Librelotto (2007) ensinam que após a independência, Mianmar adotou uma postura neutra na arena internacional, priorizando a sua reconstrução interna e apaziguamento das rivalidades étnicas, um dos maiores problemas que o país sofre, inclusive pelo fato de estar próxima de países com relevante poder, como Índia e China.

Em 02 de março de 1962, o país sofreu um golpe militar, o qual foi contemporâneo ao regime militar instituído nos diversos países da América Latina, sob a justificativa de que isso beneficiaria a população devido a recente descolonização. O Governo Militar em Mianmar permaneceu no poder até 2011. (AGÊNCIA BRASIL, 2021)

Por causa de uma crise econômica durante o período militar que acarretou no desemprego de diversas pessoas, os movimentos democráticos se fortaleceram e Aung San Suu Kui Kyi, filha do criador do Partido Comunista da Birmânia e do Partido Socialista da Birmânia, Bogyoke Aung San, se tornou um símbolo de luta pacífica pela democracia, assumindo o posto de secretária-geral do partido Liga Nacional pela Democracia (LDN), o qual confrontava com o Partido da Unidade Nacional, cujos membros eram militares.

Aung San Suu Kui Kyi incomodava os militares tendo em vista sua estratégia de unir tratativas de negociação com atos de desobediência civil, que determinaram a sua prisão em 1989. Entretanto, isso não impediu que, em 1990, o partido LDN vencesse as eleições.

Na década de 90, a Junta Militar se negou a entregar o poder a Suu kyi e os Estados Unidos manifestou seu posicionamento de reprovação à essa atitude com base nos Direitos Humanos e "rechaçaram o envio de representante diplomático a Yangon e vetaram o possível auxílio econômico dos fundos internacionais."

Em 2016, Aaung San Suu Kyi se tornou Conselheira de Estado, assumindo liderança pró-democracia. Contudo, foi criticada por não dedicar a devida atenção ao conflito que dizima o povo rohingya. Sua popularidade fez com que o partido LDN vencesse as eleições de 2020, contudo, a reação militar argumentava que as eleições foram fraudulentas sem nada provar. Em $1^{\circ}$ de fevereiro de 2021, as tropas militares ocuparam os prédios do Senado e do 
Parlamento com base no estado de emergência imposto. Após isso, tanto a mídia quanto as redes sociais passaram a ser controladas e as informações são escassas. O pouco que se sabe sobre o golpe é graças ao trabalho de jornalistas que vão a Bangladesh para divulgar informações.

O golpe militar interrompeu uma década de governo civil democrático em Mianmar e a presença militar não é aceita pela população de Myanmar há anos e, por isso, há manifestações diárias nas ruas exigindo o retorno da democracia. Os militares têm reagido de forma violenta e em pouco tempo, 400 pessoas foram detidas por questões políticas em pleno desrespeito ao direito de reunião, o qual é uma liberdade pública garantida que impõe ao Estado o dever de se abster de usar força excessiva contra os titulares desse direito, contudo, não é isso o que acontece, afinal, é comum o uso de gás lacrimogênio, canhões de água, balas de borracha e munições letais.

O Estado de emergência encontra-se previsto no Capítulo XI da Constituição do Estado de Mianmar de 2008, entretanto, a possibilidade de fraude em eleição não é uma das causas ensejadoras. Assim, a intervenção militar em um estado de defesa inexistente é inconstitucional.

Em agosto de 2021, o Min Aung Hlaing que liderou o golpe militar se autoproclamou primeiro-ministro de um governo de transição e os militares se comprometeram a convocar eleição em 2023, sendo que, quando golpearam em 2020, disseram que o fariam em 2022, logo, fica difícil confiar nas palavras de um governo que não cumpre com suas promessas. (LIY, 2021)

Desde 19 de abril de 1948, Myanmar é membro da Organização das Nações Unidas e de outras agências, tais como Organização das Nações Unidas para a Agricultura e Alimentação e Fundo das Nações Unidas para a Infância, o que demonstra que o país propugna pela manutenção da paz e segurança internacional.

Chama atenção o fato de que na Ásia ainda não existe um sistema regional específico de proteção aos direitos humanos, tal como o Sistema Europeu, o Interamericano e o Africano, entretanto, isso não deixa o país livre para violar direitos humanos, os quais são da classe jus cogens, logo, têm aplicabilidade imediata.

Mazzuoli (2015, p. 155) lamenta o fato de o Continente Asiático ter ficado à margem de qualquer expectativa regional em matéria de proteção aos direitos humanos, eis que não há 
expectativa de criação de um tratado de proteção internacional sub-regional na região asiática, o que faz com a Ásia seja a mais atrasada na proteção aos direitos humanos.

Todavia, é importante destacar que a Declaração Universal dos Direitos Humanos de 1948 é uma norma costumeira e, por isso, reivindicável pela população de Mianmar e de qualquer outro país asiático, afinal, como estes países jamais lhe mostraram contrariedade, não se pode dizer que poderá desobedecê-la com base na teoria do objetor persistente.

O país viola diversos direito elencados na Declaração Universal dos Direitos Humanos, tais como a igualdade, em virtude do tratamento desigual fundado na etnia e na religião que tem levado ao extermínio da minoria roryinga; devido à repressão contra os manifestantes ao militarismo, Mianmar viola o art. $5^{\circ}$, que impede a tortura e o tratamento cruel, desumano e degradante e ao $9^{\circ}$, que impede a prisão e a detenção arbitrária.

Outra violação aos direitos humanos perpetrada no golpe militar em Mianmar é o controle de redes sociais, conduta que viola o art. 12 da Declaração Universal de Direitos Humanos, que impede a intromissão estatal arbitrária na vida privada do indivíduo, assim como à sua correspondência.

$\mathrm{O}$ art. 21 da Declaração Universal dos Direitos Humanos estabelece que "a vontade do povo é o fundamento da autoridade dos poderes públicos: e deve exprimir-se através de eleições honestas a realizar periodicamente por sufrágio universal e igual, com voto secreto ou segundo processo equivalente que salvaguarde a vontade do povo."

O ocorrido em Myanmar foi desprezar a vontade soberana, praticamente, anulando os efeitos de uma eleição que, até o presente momento, não há provas de que foi desonesta. Além disso, toda pessoa tem direito de tomar parte na direção de seu país, mas o inverso não é direito humano: destituir, indevidamente, quem está no poder. Antônio Guterres declarou que "é absolutamente inaceitável mudar os resultados da eleição e a vontade do povo" (G1, 2020)

O Governo instalado em Mianmar, na verdade, não é um governo de direito, eis que não alcançou o poder pelos meios constitucionalmente previstos para tal, mas, sim, um governo de fato tendo em vista estar ocupando o poder após um golpe de estado contra o governo legalmente constituído.

Desse modo, resta claro que o regime ditatorial implementado em Mianmar viola direitos humanos, em nada se assemelha ao direito à autodeterminação dos povos, mas, sim, ao desrespeito à vontade soberana depositada na forma de voto presidencial. Neste caso, cabe aos países escolherem se irão adotar atitudes com base nas conhecidas Doutrina Tobar ou 
Doutrina Estrada relacionadas ao reconhecimento de Governo, as quais serão analisadas nos itens a seguir.

\section{2- DOUTRINA TOBAR E A POSSIBILIDADE DE FINALIZAR RELAÇÕES DIPLOMÁTICAS}

O golpe militar, que ensejou a destituição inconstitucional do Governo democraticamente eleito em Mianmar, Win Myint ressalta a importância das doutrinas de reconhecimento de Governo, eis que irão guiar as decisões dos demais Estados que se relacionam diplomaticamente com Mianmar.

Neste sentido, Varella (2019, p. 259) discorre a respeito da necessidade de reconhecimento de governo nos casos de mudanças bruscas no poder de um determinado país, in fine:

o reconhecimento do novo governo ocorre no contexto de um Estado já reconhecido, mas cuja direção política é alterada. Não gera problemas quando há manutenção da linha política, mas se faz necessário quando há alterações bruscas no regime político, por exemplo, golpes de Estado ou revoluções. (VARELLA, 2019, p. 259)

Desse modo, observa-se que não basta a troca de governo para que os demais Estados decidam se irão reconhecê-lo ou não, eis que é essencial que a troca tenha decorrido em subversão da ordem constitucional, em desrespeito à soberania popular.

Uma das formas que um Estado adota quando decide reconhecer a legitimidade de um novo governo é a manutenção de relações diplomáticas com o país cujo Governo foi alterado. Inclusive, quando um novo Governo é empossado, existe o costume de os demais Estados enviarem representantes de alto escalão para a cerimônia de posse do novo Governo, a fim de

mostrar reconhecimento.

No tocante à troca abrupta de Governo em Mianmar, os Estados da sociedade internacional, tais como, por exemplo, Estados Unidos e França, assim como a Organização das Nações Unidas não se mostraram indiferentes e declararam a contrariedade à violação à democracia ocorrida com a retirada do poder, à força, do então Presidente de Mianmar, Win Wyint. 
A Assembleia Geral da Organização das Nações Unidas publicou a Resolução no A/HRC/S-29/L.1, em 12 de fevereiro de 2021, na qual condenou a destituição do Governo democraticamente eleito em 08 de novembro de 2020, a suspensão dos mandatos de todos os parlamentos e apelou à restauração da democracia, assim como pela libertação das pessoas detidas arbitrariamente.

Essa Resolução foi editada em virtude do art. $13, \S 1^{\circ}$ da Carta da ONU, que permite que a Assembleia Geral iniciará estudos e fará recomendações destinados a promover cooperação internacional e favorecer o pleno gozo dos direitos humanos e das liberdades fundamentais, por parte de todos os povos, sem distinção de raça, língua e religião. Contudo, Mazzuoli (2015, p. 688) ensina que recomendações oriundas da Assembleia Geral das Nações Unidas não são dotadas de coercitividade, tendo mero caráter recomendatório, diferentemente das decisões do Conselho de Segurança, que possuem força cogente e são de cumprimento obrigatório.

Assim, tendo em vista que a Resolução da Assembleia Geral das Nações Unidas não tem caráter obrigatório, ficará de acordo com a vontade dos Estados a reconhecer, ou não a junta militar que destituiu Win Myint do Governo. Os países, a fim de ajudar Mianmar a restaurar a sua democracia, pode optar por não reconhecer o novo governo que, sem nenhum acervo probatório que comprovasse a alegada fraude eleitoral, destituiu o Presidente democraticamente eleito. Contudo, uma indagação surge: como conciliar o direito de não reconhecer um Governo com o princípio da não ingerência em matéria estatal?

Em 1907, o Ministro das Relações Exteriores do Equador Carlos Tobar esclareceu a importância de condicionar o reconhecimento de um novo Governo a fim de evitar o reconhecimento de regimes acidentais, decorrentes de revoluções, até que, finalmente, o Governo comprovasse sua aprovação popular. (VARELLA, 2019, p. 261)

É pacífico o entendimento de que golpes de Estado não acarretam perda de personalidade jurídica do Estado, entretanto, de acordo com Mazzuoli, caso a alteração no regime de governo ocorra de forma e abrupta, o reconhecimento dos demais Estados ao novo governo não se operaria de forma automática, conforme é possível verificar in fine:

quando tais modificações internas ocorrem dentro de um quadro inconstitucional a exemplo das deflagradas em um contexto de uma guerra civil, torna-se necessário que os governos que ascenderam ao poder por meio de golpe de Estado sejam reconhecidos pelos demais componentes da sociedade internacional. (MAZZUOLI, 2015, p. 507) 
Todos os Estados são livres para escolher o regime e o governo, entretanto, a partir do momento em que a troca foi de uma democracia por uma ditadura, em que a insatisfação popular é tamanha a ponto de ser sido instituído um governo paralelo, é necessário avaliar como a sociedade internacional pode agir frente às demandas populares de Myanmar.

A Doutrina Tobar sustenta que é necessário negar reconhecimento a governos que alcançam o poder indevidamente por meio de golpes de Estados ou de revoluções internas, principalmente quando for em violação à Constituição. Para essa doutrina, o novo governo só poderia ser reconhecido quando demonstrasse aprovação da população.

Apesar de o art. $8^{\circ}$ da Convenção sobre os Direitos e Deveres dos Estados de 1933, assinada em Montevideo, estabelecer que "nenhum Estado possui o direito de intervir em assuntos internos e externos de outro", a verdade é que nenhum Estado que discorde da postura do outro, principalmente quando este outro Estado viola direitos humanos, é obrigado a manter relações diplomáticas com um país cujo governo é ilegítimo.

Além disso, não reconhecer o novo Governo de Mianmar é justamente respeitar o direito de autodeterminação dos povos, o qual foi rechaçado pela junta militar.

Neste sentido, o art. 2 da Convenção de Viena sobre Relações Diplomáticas, assinada em 1961, prevê que "o estabelecimento de relações diplomáticas entre Estados e o envio de Missões Diplomáticas permanentes efetua-se por consentimento mútuo" e o art. $9^{\circ}$ da mesma Convenção estabelece que o Estado acreditado pode, a qualquer momento e sem precisar justificar a sua decisão, notificar ao Estado acreditante que o Chefe da Missão ou qualquer membro desta é persona non grata.

Assim, de acordo com Silva, Casella e Bittencourt Neto (2012, p. 199), o direito de despedida é correlativo ao direito de admissão e que, na prática, não é necessário que o agente diplomático cometa alguma falta grave para ser declarado como persona non grata, o que, para o caso em estudo, é interessante, tendo em vista que o corte das relações diplomáticos não encontra fundamento em má-conduta diplomática, mas, sim, na falta de desejo do Estado acreditado em manter relações diplomáticas com um Estado acreditante que não respeita a vontade do seu povo.

Sendo normais as relações entre os dois Estados, a declaração de personalidade não grata é evitada por meio de entendimentos oficiosos que resultam ou na transferência do funcionário faltoso para outro Posto ou na sua chamada de volta ao 
respectivo país. De uns tempos para cá, alguns Governos não têm esperado a resposta do Estado acreditante (...). Nesses casos, frequentemente, o funcionário não praticou nenhuma falha, sendo a sua retirada pedida com finalidade política, quando não demagógica. Nesse caso, o Estado acreditante vê-se obrigado a ceder a fím de evitar que o indigitado seja sujeito a alguma medida de coerção. (SILVA, CASELLA, BITTENCOURT)

O fim de relação diplomática com diversos países assim como eventuais cortes econômicos, certamente, levariam, consequentemente, ao Estado de Mianmar a uma crise social e econômica, e, por isso, é importante que os governos de países que cortem relações estejam cientes de que isso pode resultar em futuros pedidos de refúgio, afinal, não se pode negar a relação direta entre regimes autoritários e o aumento de número de refugiados.

Ao adotar a doutrina Tobar de reconhecimento de Governo, o país, apesar de não estar intervindo diretamente na política de Mianmar, estará criando dificuldades para o desenvolvimento socioeconômico do país, logo, nada mais justo do que ser receptivo aos pedidos de refúgio, pois, de acordo com Guerra e Costa, refúgio é um direito pré-existente do indivíduo:

O refúgio não é um instituto jurídico que nasce da vontade de um Estado soberano de ofertar proteção a um cidadão estrangeiro que se encontra em seu território. É tão somente o reconhecimento de um direito pré-existente à demanda formal do indivíduo. Questionamentos ao conceito de refugiado, há tempos, são levantados frente à insurgência de novos desafios impostos à comunidade internacional, como indica o número crescente de pessoas deslocadas em decorrência da miséria extrema ou mesmo os migrantes por razões ambientais. (GUERRA; COSTA, 2018, p. 210)

Esse aumento do número de refugiados não é inesperado, eis que nos anos 90, atos unilaterais de terceiros Estados levaram ao aumento de pedidos de refúgio de pessoas oriundas de Mianmar. No passado, quando a Junta Militar, na década de 90, se negou a passar o poder a Aung San Suu Kyi e, ainda assim, a Asean admitiu Mianmar como membro, os Estados Unidos instaurou um embargo econômico contra o país, entretanto, Hadar (2001, p. 415) alertava que sancionar Mianmar não adiantaria, eis que os militares não se afastariam do poder e o povo, a maioria contrária aos militares, é quem mais sofreria os impactos negativos, em virtude do aumento da miséria e de doenças.

Isso significa que os Estados da sociedade internacional podem ajudar no restabelecimento da democracia ao cortar relações diplomáticas e econômicas com Miamnar em virtude do não reconhecimento de governo baseado na Doutrina Tobar, e isso não afrontaria a Carta da ONU, eis que o próprio Conselho de Segurança foi impedido de tomar as 
providências contidas no Capítulo VII deste documento legislativo em virtude do veto da China, membro permanente, que, em aparente adesão à Doutrina Estrada, preferiu não se envolver na política interna de Mianmar, como será estudado no item a seguir.

\section{3- A NEUTRALIDADE (IN)CONVENIENTE DECORRENTE DA DOUTRINA}

\section{ESTRADA}

De acordo com Varella (2019, p. 260), o Ministro das Relações Exteriores do México, Genaro Estrada, deixou clara a opção do Estado mexicano em não se pronunciar mais a respeito de condicionantes ao reconhecimento de outros Governos, afinal, "tais critérios eram usados conforme a conveniência das potências europeias para aceitar ou não o reconhecimento dos Estados latino-americanos." Essa escolha foi em virtude do momento histórico vivenciado na América Latina de descolonização recente

A Doutrina Estrada sustenta, com base no princípio da não intervenção, que não cabe aos países da sociedade internacional reconhecer ou não o governo de outra nação. Inclusive, de acordo com o art. 1.2 da Carta das Nações Unidas, os seus membros se comprometem a “desenvolver relações amistosas entre as nações, baseadas no respeito ao princípio de igualdade de direitos e de autodeterminação dos povos, e tomar outras medidas apropriadas ao fortalecimento da paz universal."

Nesse sentido, a Doutrina Estrada conclui que condicionar o reconhecimento de Governo aos demais Estados seria uma forma de intervenção, logo, uma violação a direitos fundamentais do Estado, como soberania e igualdade jurídica. Rezek (2012, p. 224) conclui que a prática das últimas décadas, o que os Estados apenas se atentam ao reconhecer o novo Governo é a sua efetividade, sendo efetivo o governo, deve ser reconhecido "em um mundo em que a busca da legitimidade ortodoxa talvez importasse bom número de decepções."

Guerra (2019, p. 179) ensina que o princípio da não intervenção exclui o uso da força armada de um Estado contra o outro e, também, "qualquer outra forma de interferência ou de tendência atentatória à personalidade jurídica do Estado e dos elementos políticos, econômicos e culturais que o constituem.” Além disso, Guerra (2019, p. 179) ainda aponta que forçar a mudança na forma de Governo também constitui intervenção indevida de um Estado nos negócios do outro. 
Contudo, caracterizar o golpe ocorrido em Mianmar que destituiu um Governo democraticamente eleito, com base em fraudes não comprovadas, o qual levou a milhares de prisões e mortes de militantes contrários à repressão de liberdades públicas (que são direitos humanos) como manifestação de autodeterminação dos povos? O povo de Mianmar não está se autodeterminando, mas, sim, tendo a sua vontade política completamente desrespeitada, sendo necessário reforçar que o Direito Internacional é uma excelente ferramenta para proteger direitos humanos quando o Estado violador nada faz para proteger os seus nacionais (dele mesmo).

Como bem alerta Sémelin (2009, p. 189), "quanto mais os agentes capazes de intervir eficazmente na crise demoram a fazê-lo, mais a margem de atuação se estreita. Quando continuam a se manter passivos, a dinâmica conflituosa tem todas as chances de crescer, potencialmente, para, afinal, revirar-se em guerra." Logo, o risco que os Estados assumem ao adotarem a Doutrina Estrada da não intervenção é estimular que outros Governos golpistas, inspirados pela ambição, sintam-se estimulado, pela impunidade, a reverter a ordem constitucional, afinal, as relações diplomáticas e econômicas, neste caso, subsistiriam.

No Capítulo VII da Carta da ONU encontra-se expressa a competência do Conselho de Segurança das Nações Unidas para restabelecer a paz e impedir atos de agressão por meio de recomendações, tais como interrupção completa ou parcial das relações econômicas, dos meios de comunicação ferroviários, marítimos, aéreos dentre outros, contudo, a China impediu, por meio do seu poder de veto, que o Conselho de Segurança das Nações Unidas adotasse uma resolução com caráter mandatório contra a violação aos direitos humanos perpetradas por militares no país em virtude de Mianmar ser seu parceiro econômico importante.

Em outras palavras, o Conselho de Segurança das Nações Unidas, que é a organização internacional mais importante do mundo em virtude do seu caráter universal e dos temas que lhe compete optou pela Doutrina Estrada de reconhecimento de governo, eis que, apesar de condenar a situação de Mianmar, se autolimitou em virtude do veto chinês, não podendo aplicar eventuais sanções contra Mianmar por questões de interesses comerciais.

A neutralidade em um mundo globalizado, no qual os problemas que ocorre em uma parte do planeta acaba, em maior ou menor grau, afetando outros países, apenas fortalece o poder do opressor que, sem encontrar limites na ordem internacional, subverte, cada vez mais, a ordem interna. Assim, critica-se o posicionamento neutro do Itamaraty brasileiro, que 
apenas declarou que deseja o retorno à normalidade em Mianmar e que não interfere nos assuntos internos de outros países, por isso, não utiliza termos como golpe militar e presos políticos, termos estes que não são economizados quando se fala em Bolívia, Venezuela ou outros países cujo governo é de esquerda.

De acordo com Sémelin (2009, p. 182), apesar de aceita, a expressão comunidade internacional é estranha, pois “o internacional pode ser tudo, menos comunitário, de tal forma que os interesses dos Estados são, muitas vezes, contraditórios (...). Sublinhemos que, frequentemente, a suposta comunidade internacional parece não ver a crise chegar ou finge não a ver."

Essa cegueira aos problemas que acontecem nos outros Estados não são acasos, mas propositais, pois ainda que determinado Estado viole a própria Constituição e Direitos Humanos, parece ser preferível consagrar interesses econômicos internacionais, questões que, inclusive, hierarquicamente, ficam abaixo das normas de classe jus cogens.

Qualquer que seja o lado enfocado, a violência já se exprimindo em determinado país ou região não se choca, no plano internacional, a obstáculo algum, ou proibição, capaz de refreá-la. Os agentes locais, eventualmente, podem estar sendo protegidos, ou, assim pensarem, por alguma grande potência que, de certa forma, oferece cobertura internacional de primeiro plano. Essa proteção contribui para lhes garantir um sentimento de impunidade e, também, dissuadir outros Estados de intervirem diretamente na crise. (SÉMELIN, 2009, p. 182)

Diferentemente do Brasil e do Conselho de Segurança das Nações Unidas, países como Estados Unidos e França condenaram, politicamente, o golpe e pediram a libertação dos detidos arbitrariamente e, para fazer cumprir a sua vontade, congelaram os seus ativos financeiros (CANINEU, ESCUDEIRO 2021), em clara opção à doutrina Tobar de reconhecimento de governo, eis que não se limitaram a apenas condenar, mas de promover ações prejudiciais a Mianmar.

Desse modo, resta aos Estados cujos governos são conscientes de que direitos humanos são regras jus cogens, cuja aparição, nas palavras de Accioly, Silva e Casella (2019, p. 126), "veio mostrar que mesmo a vontade dos estados tem de encontrar limites", escolher a doutrina Tobar em solidariedade ao povo de Mianmar.

Além disso as normas de direitos humanos são de eficácia erga omnes, ou seja, além de hierarquia internacional superior por serem jus cogens, abrange a todas as pessoas, independentemente de nacionalidade ou de tratado internacional de direitos humanos 
assinado. Caberá aos Estados que decidirem abandonar a neutralidade, por meio de ato unilateral, ajudar no retorno da democracia em Mianmar por meio de finalização de relações diplomáticas, eis que com base na doutrina Tobar, não são obrigados a reconhecer o novo governo.

\section{4- O QUE É POSSÍVEL SER FEITO POR MIANMAR}

Diante das discussões que suscita a tomada de poder indevida pelos militares, a fim de restaurar a democracia no país, seria importante que os militares de Mianmar e demais forças de segurança do país tomassem medidas para proteger direitos constitucional e internacionalmente protegidos, tais como a liberdade de opinião, de expressão, religião, crença, reunião pacífica, dentre outros.

A fim de respeitar a manifestação de pensamento, é essencial que seja determinado o fim de qualquer restrição à liberdade de informação, por qualquer meio de comunicação, inclusive, internet e redes sociais, afinal, um país no qual as pessoas precisam se locomover para o país vizinho (Bangladesh) para difundirem suas ideias tem características autoritárias.

Já no tocante à liberdade de locomoção, recomenda-se que as pessoas que foram presas arbitrariamente sejam soltas.

Caso a democracia não volte a ser novamente usufruída, que os Estados da sociedade internacional tomem atos unilaterais baseados na doutrina Tobar de reconhecimento de governo e cortem relações diplomáticas ou econômicas com Mianmar, afinal, este país está violando normas jus cogens, logo, comete atos ilícitos internacionais.

Como afirmam Accioly, Silva e Casella (2019, p. 128, "nenhum Estado, ao violar obrigação internacional de proteção, pode se eximir de sua responsabilidade internacional, sob alegação de que tal domínio constituía, essencialmente, matéria de competência nacional ou de seu domínio reservado."

Tendo em vista que o Conselho de Segurança da Organização das Nações Unidas, devido ao veto chinês, já se mostrou impossibilitado de adotar alguma resolução mandatória para auxiliar na restauração da democracia, em claro atendimento aos ditames da Doutrina Estrada de reconhecimento de governo, seria válido que o Alto Comissariado das Nações Unidas para Direitos Humanos monitore os direitos humanos em Mianmar, mesmo quando a 
normalidade se estabelecer, por um período a ser decidido, a fim de verificar eventuais novas tentativas de golpe militar.

Situações como essas nas quais países se sentem incomodados com a violação a direitos humanos perpetrados por outro Estados mostram o quão seria importante a instalação de uma Corte Mundial, algo que ainda não existe. O máximo que existe em matéria de julgamento de Estados é a Corte Internacional de Justiça, mas, segundo Ramos (2015, p. 59), ela se autolimitou, sustentando que "o conceito de obrigações erga omnes não implica, automaticamente, na aceitação pela comunidade internacional de um foro obrigatório com competência para processar e julgar Estados acusados de violarem direitos humanos, por provocação por Estados terceiros.

Apesar de Mianmar ser membro da Corte Internacional de Justiça eis que é membro da Organização das Nações Unidas desde 1948, ainda não aceitou a sua competência contenciosa, logo, não há como instaurar um processo contra a Corte.

Os Governos dos demais Estados devem se atentar para o fato de que ninguém mais do que a junta militar de Mianmar está violando o direito à autodeterminação dos povos e outras liberdades públicas fundamentais, a ponto de ter sido criado um governo paralelo, presidido por Dwa Lashi La, o qual reúne forças contrárias ao regime instituído no país para guerrear contra a junta militar golpista (LIY, 2021)

Logo, é possível perceber a importância de se refletir a respeito da Doutrina Tobar e Doutrina Estrada de reconhecimento de governo, afinal, são elas que poderão servir de instrumento para combater ou perpetuar o sentimento de impunidade de governos golpistas ou que subiram ao poder em desacordo com a ordem constitucional.

\section{CONCLUSÃO}

A partir da leitura do presente artigo, é possível concluir que se instalou um regime militar ditatorial em Mianmar, onde direitos humanos, especialmente os referentes às liberdades públicas (liberdade de locomoção, direito de reunião, direito à liberdade de expressão, direito à vida, dentre outros) foram violados e que os países, ao adotar a neutralidade, estimulam a perpetuação de violações a direitos humanos.

O governo instalado pelos militares em Mianmar é ilegítimo, apesar de reivindicar para si poderes constitucionais que permitem aos militares assumir o poder em caso de 
emergência nacional, entretanto, justamente a falta de emergência nacional fez com que a tomada militar do poder não goza de aceitação popular e é inconstitucional, logo, não há que se reconhecer um governo que alcançou o poder em virtude da ambição e em violação à Constituição do Estado de Mianmar.

A escolha pela doutrina Estrada no tocante à aceitação de governo significa aderir, ainda que por omissão, à violação aos direitos humanos, eis que a manutenção de relações diplomáticas e econômicas com Mianmar apenas fortalecerá a Junta Militar, que galgará assentimento na sociedade internacional para continuar oprimindo liberdades públicas. Pior, isso estimulará que governos de outros países façam o mesmo e, como consequência extrema, não será impossível que o mundo passe a correr um risco generalizado de assunção de governos autoritários.

Assim, critica-se a postura da China que usou o seu poder de veto para evitar a atuação do Conselho de Segurança da ONU e de países que, como o Brasil, adotaram a neutralidade, a qual serve para estimular golpes, fortalecem governos que subiram ao poder em desconformidade com a Constituição e servem de exemplo para que os demais países não intervenham na crise.

Cabe a sugestão para que os Estados optem pela Doutrina Tobar e não reconheçam o Governo de Mianmar até que a democracia fosse restaurada, pois como os demais Estados da sociedade internacional, em virtude da Convenção de Direitos e Deveres dos Estados e da Carta da ONU, não podem impor a democracia na soberana Mianmar, resta-lhes apenas não reconhecer o governo e cortar relações econômicas e diplomáticas a fim de enfraquecer o poderio militar sobre a população.

Certamente, essa conduta de não reconhecer o Estado acarretará o aumento de pedido de refúgio feitos pelo povo de Mianmar, cabendo aos demais Estados da sociedade internacional interessados na defesa dos direitos humanos deferir tais pedidos, uma vez que o refúgio não é um favor, mas, sim, um direito humano reconhecido a todo aquele passível de sofrer perseguições em seu território.

\section{REFERÊNCIAS}


AGÊNCIA BRASIL. Itamaraty monitora situação de brasileiros em Myanmar. Disponível em: https://agenciabrasil.ebc.com.br/internacional/noticia/2021-02/itamaratymonitora-situacao-de-brasileiros-em-myanmar. Acesso em: 18 de setembro de 2021.

BBC. Quem são os rohingyas, povo muçulmano que a ONU diz ser alvo de limpeza étnica. Disponível em: https://www.bbc.com/portuguese/internacional-41257869. Acesso em: 17 de setembro de 2021.

CANINEU, Maria Laura; ESCUDEIRO, Renata. O Brasil deve condenar o golpe em Mianmar. Disponível em: https://www.hrw.org/pt/news/2021/03/11/378172. Acesso em: 13 de setembro de 2021.

G1. Chefe da ONU pede pressão para que golpe em Mianmar fracesse; facebook é bloqueado no país. Disponível em: https://g1.globo.com/mundo/noticia/2021/02/04/chefeda-onu-pede-pressao-para-que-golpe-em-mianmar-fracasse-facebook-e-bloqueado-nopais.ghtml. Acesso em: 14 de junho de 2021.

GUERRA, Sidney. Curso de Direito Internacional Público. 12. Ed. São Paulo: Saraiva, 2019.

GUERRA, Sidney; VAL, Eduardo Manuel; GUERRA, Caio Grande. Fluxos migratórios mistos para as Américas: uma abordagem jurídica. Curitiba: Instituto Memória, 2018.

HADAR, Leon T. Burma: US foreign policy as a morality play. Journal of International Affairs, New York, vol. 54, n. 02, p. 411, spring 2001.

LIY, Macarena Vidal. Governo paralelo de Mianmar declara guerra defensiva contra a junta golpista. Disponível em: https://brasil.elpais.com/internacional/2021-09-07/governoparalelo-de-mianmar-declara-guerra-defensiva-contra-a-junta-golpista.html. Acesso em: 17 de setembro de 2021.

MAZZUOLI, Valério de Oliveira. Curso de Direito Internacional. 9 ed. São Paulo: Revista dos Tribunais, 2015.

ORGANIZAÇÃO DAS NAÇÕES UNIDAS. Assembleia Geral. Resolução no A/HRC/S29/L.1. de 21 de fevereiro de 2021. Disponível em: https://undocs.org/en/A/HRC/S-29/L.1. Acesso em: 12 de setembro de 2021.

SÉMELIN, Jacques. Purificar e destruir: usos políticos dos massacres e dos genocídios. Tradução: Jorge Batos. Rio de Janeiro, Difel, 2009. 
SILVA, G.E. do Nascimento; CASELLA, Paulo Borba; BITTENCOURT NETO, Olavo de Oliveira. Direito Internacional Diplomático: Convenção de Viena sobre relações diplomáticas na teoria e na prática. São Paulo: Saraiva, 2012.

RAMOS, André de Carvalho. Processo Internacional de Direitos Humanos. 4. Ed. São Paulo: Saraiva, 2015.

RESEK, José Francisco. Direito Internacional Público: curso elementar. 9. Ed. São Paulo: Saraiva, 2002.

RUZZA, Stefano. O país está vivo, mas não muito bem: a difícil vida da democracia em Mianmar. In: Café História. Tradução de Bruno Leal Pastor de Carvalho. Original em: The Loop. Publicado em 12 abr. de 2021. Disponível em: https://www.cafehistoria.com.br/adificil-vida-da-democracia-em-mianmar/. Acesso em: 17 de setembro de 2021.

VARELLA, Marcelo D. Direito Internacional Público. 8. Ed. São Paulo: Saraiva, 2019.

XAVIER, Nathaly; LIBRELOTTO, Taís. Mianmar: o país da desconfiança ocidental. Disponível em: https://www.ufrgs.br/nerint/folder/artigos/artigo24.pdf. Acesso em: 17 de setembro de 2021. 